\title{
Relationship between Motivation and Job Performance at the University of Mines and Technology, Tarkwa, Ghana: Leadership Lessons
}

\author{
Anthony Afful-Broni \\ Faculty of Educational Studies, University of Education, Winneba, Ghana \\ Email: aabroni50@gmail.com
}

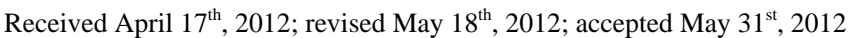

\begin{abstract}
This study examined the relationship between motivation and job performance of staff at the University of Mines and Technology, Tarkwa and the leadership lessons to be derived. A sample of 200 respondents comprising 40 senior members, 60 senior staff and 100 junior staff was employed using the purposive and simple random sampling methods. The study was guided by four research questions, and a self-developed four-point Likert structured questionnaire was the main instrument used in collecting data. The questionnaire had reliability co-efficient of $0.785,0.765,0.626$ and 0.855 respectively. Data collected was analysed with descriptive and inferential statistics. Low monthly salaries and the general lack of motivation were the major factors that reduce morale for high performance at the University. Recommendations included the need to encourage the University Council and other stakeholders to support management in developing income generating programs internally to help provide adequate incentives and allowances for the staff of the University.
\end{abstract}

Keywords: Motivation; Job Performance; Employee-Employer Relationship

\section{Introduction}

One of the most important factors that move every human being to achieve his or her goal is motivation. Indeed, motivation is that guiding principle that enables people to stay focused on the path of success regardless of the challenges that may be encountered. This includes personal as well as professional goals and targets (Baumeister \& Voh, 2004). Some scholars in the field believe that if this driving force did not exist, people would live in the rut of monotony and no great discoveries or interventions would have happened. According to Cory (2006), early conceptions assumed that work was an intrinsically undesirable pursuit and that workers naturally sought to do as little as possible which then translated into a sort of carrot-and-stick managerial policy.

According to Vroom (1964), motivation refers to a process governing individual choices among different forms of voluntary activities. Robbins and Judge (2008) posited that motivation is the process that accounts for an individual's intensity, direction and persistence of effort toward attaining a goal. This means that motivation determines how much efforts a person puts in his or her work, the direction to which those efforts are geared and a measure of how long a person can maintain effort. Motivation, therefore, may answer the question of why the workers of the University of Mines and Technology (UMaT) do what they do.

Motivation could be intrinsic or extrinsic. Intrinsic motivation derives from within the person. It refers to the direct relationship between a worker and the task, and is usually selfapplied. Examples of intrinsic motivation are achievement, accomplishment, challenge and competence which are derived from performing one's job well (Afful-Broni, 2004). Extrinsic motivation comes from the work environment, external to the person and his or her work. Good salary, fringe benefits, enabling policies and various forms of supervisions are good examples of this type of motivation (Mankoe, 2006).

Current notions of employee motivation started to take roots in the 1960s and sought to tailor the work environment and incentive structures to harness as much as possible workers' untapped reserves of skills, ideas and other potential benefits to an organization (Bobbins \& Judge, 2008). Turner and Lawrence (1965) suggested that a motivating job must allow a worker to feel personally responsible for a meaningful portion of the work accomplished. It must also provide outcomes which have intrinsic meaning to the individual and finally it must provide the employee feedback about his or her accomplishment.

Organizational psychologists have been wrestling with the question of the relationship between motivation and job performance for at least 50 years (Buchanan, 2006). Some researchers have however put a considerable amount of effort into attempts to demonstrate that the two are positively related in a particular fashion: a happy worker is a good worker (Katzell \& Thompson, 1990). Motivation is critically important for workers. Among other things, it puts staff into action. It also improves the level of efficiency of employees. Apart from that, it leads to the achievement of organizational goals; it builds friendly relationship and finally it leads to stability of workforce. Since individuals are unique in their own ways, it is essential that management at UMaT identify the individual needs of their employees and motivate them accordingly so as to 
bring out the best in them.

\section{Objectives of the Study}

The study was conducted to identify problems associated with work performance at UMaT; to identify, assess and analyse motivation interventions for employees at UMaT; to appraise the constraints faced by UMaT authorities in providing motivation to staff; and to determine the effects of motivation on job performance at the University. In short, the study sought to understand the relationship between motivation and job performance at UMaT and derive findings that can inform leadership and especially impact positively on employee-employer relationship for high job performance in the attainment of the goals of the University.

\section{Related Literature}

According to Davidoff (1987) individual performance is generally determined by three factors namely; Ability-the capability to do the job; Work environment-the tools, materials and information needed to do the job; and Motivation-the desire to do the job. Maslow (1943) and Alderfer (1972) believe that human beings have needs which must be satisfied if high performance is to be achieved. These are basic or existence needs such as food, water, shelter, clothing; safety needs, love needs, esteem and self actualization. According to Herzberg (1966), in order for the employee to perform, the work itself must be interesting; it must also provide opportunity for extra responsibility, recognition and promotion. Newstron (1993) and Fisher (2005) on the other hand consider money to be the key motivator for employees. Studies have however shown that money does not necessarily improve performance (Whitley, 2002; Afful-Broni, 2004).

In the view of Mayo (1880-1949), the social contacts which a worker has at the workplace are very important and that boredom and repetitiveness of tasks lead to reduced motivation. Supporting this, Vroom (1964) states that in places where work is monotonous and unchallenging, employees become easily bored as well as annoyed and demand that their work be more humanized. According to Boldman and Deal (2003), by encouraging employees to work in teams, they become more competent, motivated and flexible enough to undertake multiple tasks as well as deliver outstanding products and services required by the customers. Fayol (1949), believes in team spirit as he labels one of his fourteen management principles as "esprit de corps" (p. 40) and is convinced that when there is team spirit, work absenteeism is minimized, since employees are more loyal to their work and have no intention to deceive their team members (Afful-Broni, 2004).

To Fairweather (2005), employees will feel happier and work better if they perceive their employer as reasonable and fair. Cory (2006) contends that when workers perceive inequity, they will try to re-establish equitable changes. Leaders who develop and communicate a compelling vision of their organization can make a profound impact on employee motivation (Afful-Broni, 2004).

Employees crave for a job well done including being noticed and acknowledged when they do something well (Blanchard \& Witts, 2009). Yet what typically happens is nothing or worse yet, the assignment of more work. Blanchard and Witts (2009) posit that when firms do not take the time to actively reward the recognized good performance, the passion for the job diminishes with every unrecognized accomplishment. Employees are motivated by performance feedback with the desire to do well.

Haizlip (2008) believes that involving employees in decisions that affect them not only increases their personal commitment, but also motivates them to be advocates for their decisions. Supporting this assertion, Agarwal (2008) contends that when employees are involved in making decisions and planning the implementation of changes that affect them, they implement changes faster with higher performance than employees who are merely communicated to about the change. According to Blanchard and Witts (2009), employees greatly desire to have the tools, training, support and authority to make decisions and perform their jobs correctly.

In agreement, Across (2005) states that employees do not perform well in situations where they lack autonomy, especially after they have gained the skills to work independently. Campbell and Campbell (1998) contend that in order to ensure job and career security, it is important for employees to continually update and expand their work experiences and job skills. Growth, according to Boldman and Deal (2003) is not a fringe benefit, but rather a necessity for successful employment.

This study is informed by previous observations of misgivings observed among some staff regarding motivation interventions at UMaT. Many staff members seem despondent and do not appear to be motivated to deliver on the job, and this situation can undermine the achievement of the set goals of UMaT as Ghana's latest public university with the reenergized mission to become a centre of excellence for the training of mining and mineral related professionals for Ghana and the sub-region. Since Ghana continues to be a strong mineral producing nation in Africa, one would appreciate the need to lay emphasis on ensuring worker satisfaction in its university specially tasked to train efficient human resource base for this important sector.

In order to better appreciate the relationship between motivation and job performance among staff of UMaT, the following research questions were formulated to guide the study:

1) What are the problems associated with workers' job schedules at UMaT?

2) What motivation interventions are in place for employees at UMaT?

3) What challenges do the authorities in UMaT face in their attempts at providing motivation to their staff?

4) What are the effects of the motivation on job performance at the University?

\section{Significance of the Study}

The study would be of immense benefit to the University Council, Academic Board, Unionized Bodies and other stakeholders in that it will highlight how the concept of motivation and job performance are valued and understood and the need for all to pay attention to a variety of motivation issues or financial incentives for employees. Furthermore, the study will bring to light the different forms of motivation which will inform the design of appropriate measures aimed at bringing out the best in employees with regard to job performance. Again, the factors leading to high performance as well as causes of low performance will inform management and policy makers in their decision making. Administrators will be helped through this study to be able to use motivation not just for the sake of it but to know how, when and what type of motivation to use so 
as to achieve maximum performance of staff.

Also, the findings would assist in the development of effective managerial strategies and policies that can help in improving the administration and realization of organizational goals. The findings of this study should engender ideas that can lead to the provision of quality teaching, research and service delivery at UMaT.

\section{Study Design and Procedure}

Descriptive survey design was deemed most appropriate for the study (Easterby-Smith, Thorpe, \& Lowe, 2002). This was also due to the large sample size of 200 respondents out of a population of 361; and for the fact that descriptive survey is most appropriate when a lot of information is needed from quite a large sample of respondents (Fraenkel \& Wallen, 2000). The descriptive survey has the potential to provide a more accurate and meaningful picture of events, and seeks to explain people's perception and behavior on the basis of data gathered at a particular time. This methodological approach aided the researcher to collect data on senior members, senior staff and junior staff, both academic and non-academic staff of UMaT on variables underlying the study for conclusions to be made.

The respondents were randomly selected from the University of Mines and Technology (UMaT), Tarkwa in the Western Region of Ghana. In all, a sample of two hundred (200) respondents comprising forty (40) senior members, sixty (60) senior staff and one hundred (100) junior staff took part in the study. This constitutes about $55 \%$ of the total population of three hundred and sixty one (361) staff at the University.

Self-developed Likert structured questionnaire was the main instrument used for collecting data for the study. The questionnaire was developed using the Likert Scale format with few open-ended items, precisely, the four-point Likert Scale.

The questionnaire consisted of 5 sub-scales namely A, B, C, $\mathrm{D}$ and $\mathrm{E}$. The first part (A) dealt with biographic data. B determined motivation interventions at UMaT whiles $\mathrm{C}$ looked at problems with job performance at UMaT. Section D considered problems which management face in motivating employees and Section E the impact of motivation on job performance. The questionnaire items for Sections B, C, D and E were developed from the general research question posed for the study. To determine which questions would actually measure the relevant variables, item analysis was done. This was followed by pre-testing of the items of the questionnaire on a population of 25 staffs at the University of Education, Winneba. Items found to be irrelevant were deleted, and those not specific enough were modified before the final administration.

This scale had score values for positive statements as: Strongly Agree (SA), Agree (A), Disagree (D) and Strongly Disagree (SD). The scoring was reversed for negative statements

The reliability of the instruments was established using the Cronbach's Alpha measure of internal consistency which states that reliability co-efficient of 0.7 is an indication of the presence of a high reliability. In the view of Hoy and Miskel (1991), the Cronbach Alpha measure of internal consistency is useful when measures have multiple scored items such as attitudinal scale. The reliability co-efficient for the four main sections of the instrument were determined after correlating the results from the data collected for the study and were as follows. 0.785, $0.765,0.626$ and 0.855 . The Statistical Package for Social Science (Version 17.0) was used for the calculations.
Both descriptive and inferential statistics were used for the analyses and discussion of data collected from the field. Respondents to Sections B, C, D and E of the questionnaire were scored using a four-point Likert scale for positive statements as Strongly Agree $(\mathrm{SA})=4$, Agree $(\mathrm{A})=3$, Disagree $(\mathrm{D})=2$ and Strongly Disagree $(\mathrm{SD})=1$. The scoring was reversed for negative statements.

\section{Biographical Information}

Two hundred people participated in the study; a hundred and fifty one (151) were males and 49 were females. These workers consisted of 40 senior members, 60 senior staff, and 100 junior staff of the University of Mines and Technology (UMaT). Their ages ranged from 30 to 51 . Sixty two of them had a working experience of 5 years or below. Forty seven (47) of them had working experience of between 6 to 10 years; twenty one (21) had 11 to 15 years; seventy (70) had 15 years and above of working experience. With regard to education background, nine (9) had Doctorate degrees, 35 had Masters degrees, 30 had Bachelor's degrees, 21 had HND/Diploma; three had 3-year Post-secondary and 34 had O/A level while 23 had JHS/SHS. Forty five of the workers had other lower qualifications. On marital status, 33 were single; 158 were married; three (3) were divorced; while six (6) were widowed.

\section{Analysis of Responses to Problems with Job Performance at UMaT}

The study indicated that all three categories of staff agreed that there are problems with job performance at the University. One hundred and forty-nine (149) employees representing $74.5 \%$ of the total respondents agreed that low monthly salary reduces morale for high performance. Further, lack of motivation was identified as being the main contributory factor for poor work performance. A considerable number of respondents, to be precise, one hundred and forty-one (141) representing $70.5 \%$ attested to this. Again, majority of the total respondents, that is, one hundred and thirty-two (132) representing 66\% noted that lack of clear career progression reduces morale for high performance.

Added to the above, one hundred and twenty-nine (129) employees representing $64.5 \%$ and one hundred and twenty-six (126) employees representing $64.5 \%$ of the total respondents also attributed poor performance to inadequate facilities and being given wrong responsibility for one's skill respectively.

\section{Analysis of Responses to Motivation Interventions at UMaT}

The study found that though there are motivation interventions at UMaT, they are either inadequate or not being implemented equitably as most respondents disagreed to most statements. For example, one hundred and thirty-four (134) respondents representing $67 \%$ agreed that there is no periodic increase in salaries that takes care of inflation. Besides, one hundred and thirty (130) respondents representing $65 \%$ of the total respondents also stated that there is no opportunity for career development for all categories of staff.

The majority of respondents who agreed to this statement were the senior staff with $71.7 \%$ and junior staff with $69 \%$ respectively. A hundred and twenty-nine (129) respondents re- 
presenting 64.5\% said management does not meet employees to discuss the objectives of the University. These respondents consisted of $70 \%$ of senior staff and $71 \%$ of junior staff. Also, a hundred and twenty-eight (128) respondents representing 64\% also consented that incentives, allowances and rewards are not given for special efforts.

More so, $61.5 \%$ of the total respondents agreed that employees were not involved in decisions which were connected to their departments. Of the respondents, $60 \%$ were senior staff and $68 \%$ junior staff.

\section{Analysis of Responses to Problems Which Management Might Face in Motivating Employees at UMaT}

The study found that inadequate government funding limits the provision of good salaries and facilities. Twenty-seven (27) senior members representing $67.5 \%$, thirty-seven (37) senior members representing 67.5\%, thirty-seven (37) senior staff representing $61.7 \%$ and forty-two junior staff (42 or $42 \%$ ) expressed the sentiment that government subvention to the University is woefully inadequate. Again, twenty-one (21) senior members representing 52.5\%, thirty-six (36) senior staff representing $60 \%$ and forty-one (41 or $41 \%$ ) junior staff believe that inadequate internally generated funds limit the provision of incentives and allowances. It could thus be deduced that the University lacks funds to provide good salaries and facilities as well as incentives and allowances. Haizlip (2008) posits that lack of good salaries, facilities, incentives and allowances breeds dissatisfied employees who in turn will be unproductive. Management therefore needs to explore possible avenues to mobilize enough funds so as to be in a better position to reward deserving employees accordingly.

In responding to the statement "it is difficult to attract and retain qualified staff” only nineteen (19) senior members representing $47.5 \%$ and thirty-nine (39 or 39\%) junior staff agreed. Thirty-three (33) senior staff representing $55 \%$ however believed that attracting and retaining qualified staff is a problem for management. Senior staff believed that being a young University, management would find it difficult to attract and retain hardworking staff due to lack of funds. Fair benefits and pay are key to successful organisations that recruit and retain committed workers. In support, Fisher (2005) is of the view that without a fair, living wage an organization risks losing her best employees to a better-paying employer.

\section{Analysis of Responses to Effects of Motivation on Job Performance at UMaT}

A greater percentage of the respondents agreed that employees are keen to achieve high performance. Thirty-one (31) senior members representing $77.5 \%$; fifty-five (55) senior staff representing $91.7 \%$ and sixty-seven (67) junior staff supported the statement with only nine (9) senior members representing $22 \%$, five (5) senior staff representing $8 \%$ and thirty-three (33) junior staff disagreed. They stated among other things that motivation is rewarding and it leads to initiation and innovation and that its presence at UMaT will go a long way to boost morale of workers to bring out the best in them.

There was a $75.5 \%$ agreement to the statement "employees are prepared to take on challenging assignment for career progression”. It was observed that, employees want to progress and so they are prepared to do well on their jobs. Therefore, if career progression is absent due to lack of funds, it will breed dissatisfaction and consequently low output. On the issue of whether employees are enthusiastic to take on responsibilities, twenty-six (26) senior members representing 65\%, fifty-four (54) senior staff representing $90 \%$ and sixty-two (62) junior staff affirmed positively while fourteen (14) senior members representing 35\%, six (6) senior staff representing $10 \%$ and thirty-eight (38) junior staff objected.

A total of seventy-one percent (71\%) of the total respondents agreed with twenty-nine percent (29\%) objecting. Those who disagreed stated that discrimination during promotion is actually retiring their zeal to high output. They believe that when there is fairness, they would work enthusiastically to improve performance and standards.

\section{Conclusion and Recommendations}

In conclusion, the following significant findings of the study can be highlighted:

From the data, it was noted that the staff of UMaT is dominated by males. In many ways, this is no surprise as in many developing nations there are a greater number of males than females among staff at tertiary institutions.

It was also observed that low monthly salary or income and the general lack of motivation reduce morale for high performance at the University. Even though providing higher pay does not automatically result in higher productivity, it is important to note that generally speaking, staff is quick to point to low motivation as major cause of their lack of enthusiasm at work.

Also, the lack of clear career progression and delays in promotion can reduce morale for job performance at the University. If the majority of workers believe that management is not interested in providing a more serious and clear career progression; and if there is the perception that promotion is unduly delayed, morale at work will be negatively affected.

Another major reality is that if there are inadequate facilities to enhance one's effectiveness and efficiency at work and if workers are usually given responsibilities which do not match their skills, they would more likely perform poorly in their various fields. Senior staff and junior staff reacted strongly to issues bothering on motivation interventions at the University. They seem dissatisfied and not content with the disparities between themselves and the senior members.

Finally, it was observed that inadequate government funding is the major problem for management in motivating employees. As a state institution, it was expected that there would be greater financial support from Central Government to enhance greater productivity.

The study findings point to some important recommendations:

Firstly, the study revealed that the staff of UMaT is dominated by males. Hence, it is recommended that management, with the backing of the University Council and the Academic Board, considers employing more females to balance the gender inequality that exists there. A well developed set of programs which could eventually develop into a Gender Mainstreaming Desk as instituted in her admission of students should be developed for the workforce at UMaT.

Secondly, paramount among the problems of job performance at the University is low monthly salary as well as lack of motivation. It is believed that the University authorities do not 


\section{A. AFFUL-BRONI}

control salaries but then they could adjust their salary structures with regard to the various levels attached to each grade so that employees can enjoy better salaries. In this regard, it is being recommended that the University Council throw its weight behind UMaT's management in ensuring that the University follows regulations that enable it to be more proactive and staff friendly.

Thirdly and specifically, employees could also be cushioned by being provided with incentives, some of which are financed by internally generated funds. It is being recommended that the necessary atmosphere should continue to be created where the Unionized Bodies are welcome and empowered to work in the interest of staff motivation for greater productivity. The researcher is suggesting that situations where Unionized Bodies are wrongly perceived as foes ought to give way for a more healthy staff force.

Fourthly, it is recommended that the management of UMaT should be more innovative and proactive in creating and strategizing new measures that would ensure a fairer, logical and adequate motivation for all categories of staff. For example, there should be forums in which management would provide opportunities for staff to ask questions and be provided with candid responses aimed at showing interest in workers' needs. To further demonstrate greater commitment, promises made should be followed up and implemented so as to strengthen staff trust, morale and corresponding greater productivity.

Fifthly, lack of clear career progression and delays in promotion were also found to reduce morale for job performance at the University. In view of this, the University needs to have in place a clearly delineated framework for learning and training for all categories of staff. Promotion criteria should be clear cut and well communicated to employees so as to avoid unnecessary delays in promotion as this causes dissatisfaction and leads to low morale for performance. Concretely, the University leadership sector should develop documentation, expanding the Statutes and Conditions of Service for staff and ensuring that these documents are readily available to all. It should even be possible to upload some of these documents at the University's website for greater visibility and more staff accessibility.

Sixthly, it was established from the study that Senior Staff as well as Junior Staff are dissatisfied. The University is made up of three categories of staff. If any group of staff is dissatisfied, the University is bound to encounter needless problems. In the light of this, it is recommended that management should interpret and communicate the University's objectives and visions to all staff on a continuous basis. Channels of communication and feedback within departments as well as the entire University must be strengthened, with the prime aim of facilitating the free flow of information. Measures that would ensure the inclusion of as much as possible the views of all staff can help as this would foster a feeling of collective ownership of decisions and encourage commitment to execution. The leadership of the University should consider discussing some of these issues at Academic Board deliberations. It should be possible, from time to time, for the leadership to share information at Faculty Board or departmental meetings; this way, as many of the staff as possible would have access to the leadership and communicate more effectively. By so doing, employees would be more likely to feel as working together towards a common goal and in a common mission.

It is further recommended that the necessary facilities such as personal protective equipment for junior staff as well as office and classroom facilities for senior staff and senior members be adequately provided to better equip employees. Deliberate efforts should also be made to provide a congenial work environment by encouraging healthy superior-subordinate relationships. Faculty and Departmental festivals could be organized periodically to more concretely help provide the forum for bringing this about.

Also, it is suggested that since inadequate government funding was a major problem for management in motivating employees, internally generated funds should be sourced for to enable management deal more efficiently with motivational issues. This could be done by encouraging senior members to undertake more consultancy services, organising short courses for the mining companies and undertaking commercial activities. Such activities could be so organized as to attract stipulated taxes or commissions which can go into the internally generated funds.

Finally, efforts should be made by management to invest some of UMaT's profits from consultancies, short courses, tuition fees and academic facility user fees which could be used to support staff incentive packages.

\section{REFERENCES}

Across, R. (2005). Psychology, the science and mind and behaviour. London: Dubai for Hodder Arnold Euston.

Afful-Broni, A. (2004). Theory and practice of educational leadership in Ghana. Accra: Yamens Press Ltd.

Agarwal, A. (2008). Employee motivation. URL (last checked 25 November 2009). http://ezinearticles.com

Alderfer, C. (1972). Existence, relatedness \& growth. New York: Free Press.

Baumeister, R. F., \& Voh, K. D. (2004). Handbook of self-regulation: Research, theory and applications. New York: Guilford Press.

Blanchard, S., \& Witts, D. (2009). Best practices in employee motivation. URL (last checked 29 December 2009). http://www.buzzle.com

Boldman, L. G., \& Deal, T. E. (2003). Reframing organisation: Artistry, choice and leadership (3rd ed.). San Francisco, CA: Jossey-Bass Press.

Buchanan, K. (2006). Job performance and satisfaction. URL (last checked 24 October 2009). http://ezinearticles.com

Campbell, S. P., \& Campbell, R. S. (1988). Productivity in organizations: New perspectives from inductrial and organizational psychology. San Francisco, CA: Jossey-Bass.

Cory, C. (2006). Equity theory and employee motivation. URL (last checked 27 November 2009). http://www.buzzle.com

Davidoff, L. L. (1987). Introduction to psychology (3rd ed.). New York: McGraw-Hill.

Easterby-Smith, M., Thorpe, R., \& Lowe, A. (2002). Management research: An introduction. London: Sage Publications.

Fairweather, A. (2005). 3 steps to stop absence and make people happy at work. URL (last checked 27 November 2009). http://www.buzzle.com

Fisher, J. G. (2005). How to run successful incentive schemes (3rd ed.). London: Kojan.

Fraenkel, J. R., \& Wallen, N. E. (1993). How to design and evaluate research in education (2nd ed.). Boston, MA: McGraw Hill.

Haizlip, T. (2008). Employee motivation-10 tips to boost job performance. URL (last checked 24 October 2009).

http://www.wzinearticles.com

Herzberg, F. (1966). Work and the nature of man. Cleveland, OH: World Publishing Co.

Hoy, W. K., \& Miskel, C. G. (1991). Educational administration, theory, research and practice. New York: McGraw-Hill.

Katzell, R. A. \& Thompson, D. E. (1990). Work motivation: Theory and practice. American Psychologist, 45, 144-153. doi:10.1037/0003-066X.45.2.144 


\section{A. AFFUL-BRONI}

Lawler, E. E. (1973). Motivation in work organisations. Monterey, CA: Brooks/Cole.

Maier, N. R. (1973). Psychology in industrial organization (4th ed.). Boston, MA: Houghton Mifflin.

Mankoe, J. (2006). Educational administration and management in Ghana (revised ed.). Kumasi: Payless Publication Ltd.

Maslow, A. (1943). A theory of human motivation, psychological review, 50, 370-396. doi:10.1037/h0054346

Newstron, J. W., \& Davis, K. (1993). Organizational behaviour, human behaviour at work. New York: McGraw-Hill.

Robbins, S. P., \& Judge, T. A. (2008). Essential organisational beha- viour. Upper Saddle River, NJ: Pearson Education Inc.

Turner, A. N., \& Lawrence, P. R. (1965). Industrial jobs and the worker: An investigation of response to task attributes. Cambridge, MA: Harvard University, Graduate School of Business Division of Research.

Vroom, V. H. (1964). Work and motivation. New York: John Wiley \& Sons.

White, A. (1998). The essential guide to developing your staff. London: Piatkus.

Whitley, P. (2002). Motivation. Oxford: Capestone Publishing. 